\title{
IMPORTANCE OF HEALTH AGENTS IN THE PREVENTION OF BREAST CANCER
}

\author{
Paula de O. C. Queiroz¹, Thaynara Mercadante1, Sarah R. Santos¹, Carolina B. S. Azevedo² \\ 'Universidade Federal de Goiás - Goiânia (GO), Brazil. \\ ${ }^{2}$ Universidade de Rio Verde - Rio Verde (GO), Brazil.
}

Objective: The community health agent (CHA) are people from the own community who have been working in primary care since the 1980s. The objective of this study is to evaluate and discuss the impact of health agents in the Basic Health Units and in the community in the prevention of breast cancer. Methodology: This is a narrative review about the role of health agents in the prevention of breast cancer. The search for articles happened in the platforms SciELO and PubMed using the descriptors "primary care" and "breast cancer". The period of publications was from 2009 to 2019. Results: The revised articles were focused on primary care, as this is the field of action of CHAs, and most of them cited prevention measures that could be encouraged by these agents in the community. Thus, the dissemination of information, contributing both to primary and secondary prevention, would be the main focus of agents in breast cancer. Although there are interventions in primary care to prevent the disease, these measures have not provided the desired changes in women's health, which could indicate the depreciation of the work of this agents and the lack of support for these workers. A diet rich in vegetables, lower caloric intake, moderate carbohydrate intake, and physical activity for weight control may reduce the risk of breast cancer, as well as avoid alcohol and tobacco use. These actions can be better monitored through the CHAs's follow-up, who have a global view of the context in which the population is inserted. Conclusion: The creation of a link between the community and the team of CHAs allows a greater passive awareness, and consequently, prevention, in addition to a greater early detection of breast cancer. Therefore, they are critical for the prevention of diseases such as breast cancer. 